\title{
Proclo: el papel soteriológico de la poesía inspirada
}

\author{
Proclus: the soteriological role of inspired poetry
}

Por: José María Nieva*

Universidad Nacional de Tucumán

Email: jose_marianieva@hotmail.com

Fecha de recepción: 31/01/2019

Fecha de aprobación

$02 / 04 / 2019$

Resumen: Proclo en la disertación VI de su Comentario a la República, en la cual discute el valor de la poesía y de los mitos de Homero y de Platón, plantea lo que podríamos llamar su estrategia hermenéutica bajo un doble aspecto: mostrar que en la poesía algo va más allá del significado literal y mostrar que en la interpretación platónica de la poesía hay más de cuanto algunas afirmaciones de los diálogos dejan a primera vista entrever. En este intento de mostrar lo que hay más allá de la literalidad Proclo establece tres modos de vida del alma conforme a tres tipos de poesía: inspirada, epistémica y mimética. En ese marco se muestra de modo relevante la unificación del alma para que pueda obtener la experiencia extática con lo Uno. Se ensayará en las páginas que siguen mostrar el papel soteriológico de la poesía inspirada a la par que discutir si se puede hablar de Proclo como un teórico de la mística o de un místico en cuanto tal.

Palabras claves: poesía - mito - símbolo - salvación - alma

Abstract: Proclus in the sixth essay of his Republic Commentary, which discusses the value of poetry and the myths of Homer and Plato, raises what we could call his hermeneutical strategy under a double aspect: show that in poetry something it goes beyond the literal meaning and shows that in the Platonic interpretation of poetry there is more than what some statements in the dialogues reveal at first sight. In this

\footnotetext{
* Doctor en Filosofía por la Universidad Nacional de Tucumán (Argentina). Docente de Historia de la Filosofía Antigua y de Pensamiento Filosófico, Universidad Nacional de Tucumán (Argentina).
} 
Proclo: el papel soteriológico de la poesía inspirada

attempt to show what is beyond the literal Proclus establishes three ways of life of the soul according to three types of poetry: inspired, epistemic and mimetic. In this framework the unification of the soul is shown in a relevant way so that it can obtain the ecstatic experience with the One. It will be tested in the pages that follow to show the soteriological role of the inspired poetry as well as to discuss if one can speak of Proclus as a theorist of mysticism or a mystic as such.

Key Words: poetry - myth - symbols - salvation - soul

\section{Cómo citar este artículo:}

APA: Nieva, J. M. (2019). Proclo: el papel soteriológico de la poesía inspirada. Nuevo Itinerario, 14 (1), 229-252. Recuperado de: (agregar dirección web)

En el currículo de estudios de la filosofía neoplatónica no cabe encontrar un lugar preciso para la República de Platón. Frente a otros diálogos que han merecido un comentario pormenorizado o exhaustivo, como por ejemplo el Parménides o el Timeo, aquel diálogo platónico pareciera quedar entre las sombras excepto por la atención dedicada al libro VI, en el cual puede apreciarse en germen la estructura jerárquica de lo real para los neoplatónicos tanto en lo metafísico como en lo gnoseológico, en su célebre alegoría de la línea, o al libro $X$, muy especialmente a su segunda parte por el valor concedido al mito escatológico.

No obstante ello Proclo lleva a cabo un Comentario a la República donde se interroga, ya desde la primera disertación, acerca de la finalidad de Platón en este diálogo: ¿se trata acerca de la justicia o del mejor régimen político para la ciudad? El comentador neoplatónico responde que el objetivo perseguido por Platón es doble. Este se propone tratar a la vez del régimen político y de la justicia porque afirma Proclo

el argumento es la forma de gobierno y al mismo tiempo la justicia en su auténtico significado, como si no se tratase de dos diferentes fines, sino como si se tratase de dos fines idénticos entre sí. En efecto, lo que es la justicia en una sola alma, esto es en la ciudad bien gobernada 
absolutamente la forma de gobierno correspondiente (Comentario a la República I, 11, 10-15) ${ }^{1}$.

Detrás de estas preguntas presenta los principios de la filosofía neoplatónica a un probable grupo avezado de estudiantes de filosofía. Principios en los cuales se entretejen de una manera singular ética, metafísica y teología. En tal sentido, parecen acertadas las palabras de Sheppard (2013, p. 108) cuando dice que "la discusión acerca del objetivo del diálogo está dirigida a una audiencia de exégetas, o de futuros exégetas".

Tales principios aparecen en la disertación VI en la cual al discutir el valor de la poesía y de los mitos de Homero y de Platón, Proclo plantea lo que podríamos llamar su estrategia hermenéutica bajo un doble aspecto: mostrar que en la poesía algo va más allá del significado literal y mostrar que en la interpretación platónica de la poesía hay más de cuanto algunas afirmaciones de los diálogos dejan a primera vista entrever. Hay un entrecruzamiento entre el valor de la alegoría y del símbolo, y la construcción de una teoría platónica de la poesía bastante compleja por la alambicada relación entre distintos diálogos. Se trata al fin de cuentas de unir Homero y Platón, poesía y filosofía, en una síntesis de intuición y revelación neoplatónica; o para decirlo en otras palabras, mostrar que la querella que ha establecido Platón entre poesía y filosofía no es tan aguda e insalvable como se cree normalmente.

En este intento de mostrar lo que hay más allá de la literalidad Proclo establece tres modos de vida del alma conforme a tres tipos de poesía: inspirada, epistémica y mimética. En ese marco se muestra de modo relevante la unificación del alma para que pueda obtener la experiencia extática con lo Uno. Se ensayará en las páginas que siguen mostrar el papel soteriológico de la poesía inspirada a la par que discutir si se puede hablar de Proclo como un teórico de la mística o de un místico en cuanto tal. $\mathrm{O}$ formulado en palabras de Lamberton (1986, p.173): “¿Proclo, en sus escritos, estuvo

\footnotetext{
${ }^{1}$ Para las citas del Comentario a la República utilizamos Proclus. Commentaire sur la République, 3 vol, Paris, Vrin, 1970. Traducción de A. Festugière. Para el texto griego W. Kroll, In Platonis Rem publicam commentarii, 2 vol, Amsterdam 1965.
} 
Proclo: el papel soteriológico de la poesía inspirada

interesado en las obras de literatura como tales, o fue un intérprete primariamente de mitos, un pensador religioso y un místico para el cual el texto tiene poca importancia?"

Esta pregunta exige tener presente dos cuestiones: una, que en la filosofía neoplatónica a partir de Jámblico los diálogos platónicos poseen un skopos, un propósito u objetivo, es decir, tienen una unidad que se hace necesario desentrañar, y con ello, segunda cuestión, el valor concedido a la exégesis. Se acaba de señalar que Proclo entiende que la República posee un objetivo; no obstante, su Comentario pareciera que carece de él ya que se considera al mismo como una serie de ensayos o disertaciones escritos en momentos diferentes bajo necesidades diferentes, por tanto, careciendo de una verdadera unidad. No es posible entrar aquí en detalles para marcar que sería extraño que en un pensador tan sistemático y riguroso en sus comentarios pasase por alto tan significativa tarea de hilvanar certeramente su texto. En tal sentido, es llamativo que los estudiosos de esta obra no hayan prestado atención a que el Licio en la VI disertación hablando de la relación entre Homero y Platón acerca del Hades diga precisamente que "pero nosotros volveremos sobre este tema a continuación", lo que hará en la XVI disertación cuando se ocupe del mito de Er, el cual por cierto es llevado a cabo según lemmas, es decir, comentando a pie juntillas el texto platónico. Tiene suma relevancia, por tanto, la observación de Gritti (2012, p. 19) cuando dice que "la República no encontraba puesto en el programa escolástico, probablemente por sus dimensiones; aunque permanece incierta la naturaleza de las disertaciones que constituyen el escrito de Proclo, su tenor muy de especialista haría pensar en conferencias tenidas en presencia de lectores competentes", lo cual concuerda en cierta medida con la reciente traducción inglesa de este comentario donde en contra de la opinio communis se ofrecen razones para señalar que es "una obra no menos unificada que el propio diálogo de Platón"(Baltzly-Finamore, 2018, p.10), precisamente en cuanto la presencia de lectores competentes demanda un conocimiento de la filosofía platónica y del vocabulario técnico del pensamiento neoplatónico que hace imposible pensar que la obra fuese una rapsodia de ensayos inconexos y con propósitos particulares para cada uno. 
En cuanto a la exégesis, cobra aquí un valor singular la noción de texto y la concepción que se hacen los neoplatónicos tardíos de la filosofía. Comentar un texto es filosofar y filosofar es comentar un texto. $\mathrm{Si}$, efectivamente, el neoplatonismo es una tradición textual, según Rappe (2000, p.1), no es posible soslayar la importancia del mismo, y de ese modo, no se puede suscribir la apreciación de Lamberton de que el texto tuviera poca importancia. Si un texto es todo discurso fijado en la escritura, el comentario de texto para un neoplatónico es iluminar el discurso platónico y comprender en él y con él una verdad transmitida, es decir, el objetivo de la interpretación yace más allá de las líneas del texto para encontrar una verdad que ya ha sido descubierta, tal como Proclo lo establece en los comienzos de la Teología Platónica, verdad que manifestada en la poesía inspirada otorga a las almas su salvación.

Aunque es cierto decir que el neoplatonismo no posee en cuanto tal la noción de texto, no obstante, como bien señala Bouffartigue (1987, p.130), ella se explicita en dos nociones que se entrecruzan: parapetasma y prokalyma, pantalla y velo. Interpretar un texto es, en consecuencia, desentrañar su verdadero sentido, el cual yace más allá de las palabras escritas, es decir, desvelar una sabiduría oculta, y por cierto, se sabe que para los neoplatónicos la filosofía es una mistagogía, una iniciación en lo secreto. Pierre Hadot (2006, p.55): observa bien que "cuando se abordan los comentarios de Aristóteles o Platón redactados por los neoplatónicos uno tiene al principio la impresión de que su redacción obedece únicamente a preocupaciones doctrinales y exegéticas. Pero si se examinan en profundidad se observa que el método de exégesis y el contenido doctrinal de cada comentario están pensados en función del nivel espiritual de los oyentes a los cuales se dirigen. Es por eso por lo que existen grados de enseñanza filosófica, basados en el progreso espiritual. No les son leídos los mismos textos a los principiantes, a los que han realizado algunos progresos o a los más avanzados, y los conceptos que aparecen en los comentarios los hacen, también, en función de las capacidades espirituales del oyente. El contenido doctrinal puede, por lo tanto, variar considerablemente de un comentario a otro, pese a haber sido redactados ambos por el mismo autor. Ello no significa que se hayan producido 
Proclo: el papel soteriológico de la poesía inspirada

virajes doctrinales en el comentarista, sino que las necesidades de los discípulos eran diferentes". Y parece que las necesidades de los discípulos a los cuales está dirigida esta sexta disertación eran muy altas, es decir, de verdadera transformación interior y acceso a la verdad sagrada y oculta. En efecto, refiriéndose a la poesía inspirada Proclo señala que

el rol de la educación no es, a mi juicio, el mismo según se trate del estado de espíritu de jóvenes o de aquel de los adultos ya maduros por la política y que tienen no obstante necesidad de escuchar una lección más mística sobre lo divino. Digamos que la poesía es más que todo educativa cuando está penetrada de lo divino, y que lo divino que está en ella se manifiesta claramente a los oyentes: si en efecto uno la toca superficialmente, no puede aprehender la verdad secreta oculta en ella (In Rem I 182.5-14), lo que coincide con las palabras finales de esta disertación: "Que todo esto, queridos discípulos, sea pagado en tributo de homenaje en recuerdo de las lecciones de nuestro maestro: con cosas que yo puedo decirles, pero que ustedes no deben revelar a la multitud" (In Rem I 205.22).

Podríamos decir, entonces, para el tema que nos ocupa que Proclo busca encontrar el modo en el cual Platón no disiente con Homero y por ello quiere desentrañar el secreto que aúna ambos modos de entender la poesía.

Ahora bien, antes de abordar la pregunta que nos hemos planteado anteriormente, digamos que no es nuestra intención detenernos en la concepción procleana de la poesía y su concepción de crítica literaria así como cuánto debe a Siriano y a Platón mismo, lo cual ha sido realizado soberbiamente por Sheppard (1980); por el contrario, nos interesa su vinculación con el alma y su unificación ya que ella puede alcanzar su salvación a través de la poesía inspirada.

En efecto, Proclo señala en la VI disertación (177.15-178.10) que hay tres especies de vida del alma y que la poética se divide conforme a estas especies. Cito el texto in extenso dada su relevancia:

Nosotros decimos que hay en el alma, para hablar de modo general, tres especies de vida: una, la mejor y más perfecta, según la cual el alma se une a los dioses y vive la vida que le es más connatural y unida por la semejanza más alta, vida que no se pertenece a ella misma, sino a los dioses, donde el alma ha sobrepasado su propio intelecto, ha despertado en ella el 
synthèma inefable de la existencia unitaria de los dioses y ha atado lo semejante a lo semejante, su propia luz a aquella de allá, y a lo Uno más allá de toda esencia y de toda vida lo que hay de más semejante a lo Uno en su propia esencia y su propia vida; en segundo lugar, la manera vivir inferior a esta en dignidad y potencia, que está colocada como intermedia en el medio del alma, según la cual ella ha descendido sin duda de la vida inspirada de los dioses para convertirse a sí misma, pero, porque ella se ha propuesto intelecto y ciencia como principios de su actividad, despliega la multiplicidad de razones, contempla los cambios de toda clase de ideas, conduce a la identidad a lo pensante y lo pensado y representa la esencia intelectiva porque ella ha abrazado en una misma unidad la naturaleza de los inteligibles; además de estas dos, una tercera especie de vida, que, arrastrada en el curso de las potencias menos valiosas y que actúan con ellas, se sirve de imaginaciones y sensaciones irracionales y se colma completamente de las realidades inferiores ${ }^{2}$.

En la concepción procleana el alma se caracteriza por dos notas relevantes: automovimiento entre lo inmutable de la esencia y la errancia de la génesis, y su carácter intermedio entre lo sensible y lo inteligible, es decir, se conjugan aquí el Fedro y el Timeo platónicos. Precisamente en su Comentario a este último diálogo el Licio señala que

Toda vida es movimiento. De modo que si todo lo que vive es movido, aquello que vive por sí mismo es movido y aquello que vive siempre es movido siempre, en acuerdo con la Vida, pero no en acuerdo con el Intelecto. Por ello el alma es siempre movida y no siempre. Porque es intelecto en potencia, pero vida en actualidad (In Tim III 335.17-23. Cf. In Euc 36,17).

Pero por el pasaje anteriormente citado del Comentario a la República podemos decir que vida no es un término unívoco sino homónimo, y que si el alma es vida y por ello movimiento hay diferentes maneras en las cuales vive según sea su modo de ser, su hábito, lo que precisamente señala este pasaje. Que el término vida se entienda de diferentes maneras es algo propio en la tradición platónica si recordamos las Sentencias o Punto de partida hacia los inteligibles 16 de Porfirio que retrotrae a Enéada I 4 de Plotino. Lo relevante aquí, no obstante, se encuentra en la noción de hábito, de hexis, que ciertamente Proclo no explicita pero que podemos entender

\footnotetext{
${ }^{2}$ Proclus. Commentaire sur la République. Tome I. Traduction et notes par A. Festugiére, Paris, Vrin, 1970 (con modificaciones en la traducción).
} 
Proclo: el papel soteriológico de la poesía inspirada

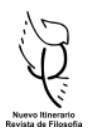

como aquello que nace del movimiento del alma, y si ella es siempre movida y no siempre, entonces su hábito depende de la orientación de su movimiento, del telos hacia el cual se dirige para expresarlo aristotélicamente, es decir, depende de la orientación que ella tome o hacia lo superior o hacia lo inferior.

Estos dos últimos términos nos permiten aclarar mejor la noción de hábito si tenemos presente el siguiente pasaje de su Comentario al Alcibíades 20.1-5 donde se dice:

Así pues, hay tres clases de conversión: porque todo lo que se convierte o bien se convierte hacia lo que es inferior como consecuencia de una caída a partir de su propia perfección, o bien se eleva hacia lo que es superior por intermedio de su propia vida y de su actividad conforme a su naturaleza o bien se convierte hacia sí mismo, por el conocimiento que le es coordinado y por el género intermedio del movimiento.

A mi modo de ver este pasaje no solo ayuda a comprender la relación entre movimiento y hábito, sino también arroja mucha luz sobre las divisiones de la poética. Si esta se divide en inspirada, epistémica y mimética, entonces hay tres modos de ser en la vida del alma según hacia donde ella se dirija, o digamos mejor, según los modos en los cuales se hace poesía y la finalidad que con ello se persigue.

Respecto de la poesía mimética ha de decirse que la noción misma de mímesis en Proclo merecería una atención particular porque su arco semántico es bien diferenciado. Según Moutsopoulos (2010, pp. 113ss) hay tres campos de aplicación: ontológico, epistemológico y estético. El primero se caracteriza porque las realidades inferiores imitan a las realidades superiores, lo cual revela la estructura jerárquica y la prioridad de lo superior sobre lo inferior; el segundo tiene que ver con el pensamiento que imita la realidad y dicha imitación se expresa y se manifiesta en el lenguaje; el tercero con la actividad creadora de la música y, para nuestro caso, con la actividad póetica. El Licio se refiere claramente con esta última actividad a lo que Platón señalaba ya tanto en la República como en el Sofista, diálogo que cita extensamente para caracterizar a la poesía mimética como productora de apariencias, es decir,

\footnotetext{
${ }^{3}$ Un buen desarrollo de este tópico se encuentra en Halliwell (2009).
} 
ceñida a to phantastikon (I 189.25). La noción de mímesis muestra aquí su significación relacionada con un arte de tipo inferior que no necesariamente expresa lo genuino, aunque debemos aclarar que la poesía imitativa o mimética se divide en dos: eikazein ta pragmata y apotypousthai phainomenōs, que Festugiére traduce como "copia los objetos" y "da un representación ilusoria". Quizá debiera traducirse mejor la primera expresión como "representa las realidades" porque Proclo señala que el poeta hace esto teniendo en cuenta el modelo sobre el cual se representan las realidades mismas, mientras que la segunda expresión sería mejor traducirla como "modela de un modo aparente". Precisamente el adverbio phainomenōs nos retrotrae al lenguaje platónico que representa al sofista como un productor de ta phantasmata, es decir, de apariencias engañosas. En efecto, Lamberton (2012, p.177) traduce estas líneas del siguiente modo: "sometimes makes [accurate] images of things and sometimes gives an illusory impression of them".

Según este intérprete $(1986$, p.189) Proclo indica que toda mímesis se relaciona exclusivamente con las apariencias (ta phainomena) y no con los seres verdaderos ( $t a$ alèthē) porque ella está confinada a la experiencia fragmentada de este mundo y no tiene referencia a la experiencia unificadora, trascendente del otro mundo. Pero este juicio puede suscribirse solo para la mimēsis phantastikē no para la mimēsis eikastikē, porque esta última tiene ciertos resabios de verdad o de realidad, no así la primera.

A ella se refiere Proclo con un término de pesada raigambre platónica, ella es una skiagraphia ${ }^{4}$, una pintura ilusoria de lo real, según la traducción de Festugiére que tiene como solo objetivo dirigirse a to pathētikon del alma operando en ella una psicagogia. Es significativo que aquí Proclo muestre la estrecha vinculación entre estética y ética en cuanto este tipo de poesía perturba el alma hundiéndola en sus propias pasiones y oscureciéndola totalmente. Digamos en lenguaje platónico hechizándola. En efecto, no en vano en República $X$ el poeta es goēs un hechicero, aquel que embruja y en el Sofista se dice que el sofista posee la técnica de goèteuein a los jóvenes al mostrar eidōla legomena peri pantōn. En efecto, Proclo refiriéndose a

\footnotetext{
${ }^{4}$ Para este tema en Platón puede verse Sekimura (2009) y Napolitano Valditara (2007).
} 
Proclo: el papel soteriológico de la poesía inspirada

Sofista 235 d-236 a caracteriza este arte como el arte de fabricar simulacros, eidolourgikēs (cf. eidolikē skiagraphia: In Alc.108.12). Merecen aquí citarse algunos pasajes de su Comentario al Alcibíades. En 49.10 se afirma que un eidōlon es una huella oscura o imprecisa por eso se denomina de ese modo, es decir, es una cierta sombra como la pintura de sombras que es efectivamente la skiagraphia, es decir, de engaño o falsedad, lo que ha de ser rechazado. Esto marca precisamente el pasaje 99.10 cuando dice:

porque despreciar lo que nos envuelve como no teniendo más realidad que una pintura de sombras (hōs eskiagraphēmenōn) y como sin valor, para investigar de preferencia a esto algo grande, admirable y que sobrepasa lo múltiple, esto es prueba evidente del deseo de lo bello que trabaja en las almas.

Tal trabajo es la búsqueda de la ciencia como lo marca el pasaje 155. 13 cuando afirma que

es pues la ciencia la que nos permite discernir entre los bienes verdaderos y los malos, y aquel que la ha adquirido no se deja fácilmente engañar por los ídolos y puede volver su mirada hacia los seres mismos ya que se ha desembarazado de las sombras de aquí abajo (pros auta ta onta dynatai blepein tōn skiagraphiōn touton apallageis).

Eidōlon y phantasma se imbrican aquí mutuamente junto con skia para implicar la noción de apariencia, incluso de apariencia falsa, de algo inauténtico porque no hay ninguna referencia a un objeto que sea auténtico y del cual haya eikones, imágenes. ${ }^{5}$ Por ello la relevancia del hechizar, del engañar y de la psicagogía que ejerce sobre las almas el poeta como un pintor de sombras.

Para obtener la ciencia entonces es necesario volverse desde las apariencias hacia los seres reales, desde el mar de la desemejanza para usar una cara expresión procleana hacia la vida del intelecto. Para ello el alma debe purificarse y tal purificación no es otra cosa que una conversión hacia sí misma al despojarse de lo pasional que anida en ella, lo que redunda en beneficio de obtener una actividad noética, lo cual significa según la magnífica expresión de Trouillard $(1982$, p.53) liberar

\footnotetext{
${ }^{5}$ Cf. Moutsopoulos (1981).
} 
"su cielo interior así como las semillas de verdad que lleva en ella". Tal es lo que marca el segundo tipo de poesía porque en ella el alma "ha descendido de la vida inspirada de los dioses para convertirse hacia ella misma, pero, porque ella se ha propuesto intelecto y ciencia como principios de su actividad, despliega (analittei ta plèthè tōn logōn) la multiplicidad de razones" (I 177.25-28).

Este tipo de poesía ha sido caracterizada por Sheppard (1980), siguiendo una nota de Festugiére, como poesía didáctica al igual que Lamberton en su introducción a la traducción de las disertaciones $\mathrm{V}$ y $\mathrm{VI}$, pero que la estudiosa inglesa reconsidera luego de las críticas que le dirigiera Beierwaltes ${ }^{6}$. En efecto, no puede ser considerada didáctica porque se conjuga aquí insoslayablemente ciencia y ética, es decir, conocimiento y virtudes, y parece mucho más relevante lo segundo que lo primero. Hay un énfasis muy fuerte en un tema caro a Platón: la virtud total, es decir, la unidad de la virtud, y sabemos que en el neoplatonismo la escala de las virtudes tiene como fin no solo la semejanza con Dios sino la unificación plena y pura del alma para recuperarse a sí misma en su verdadera naturaleza. Proclo afirma respecto de ella que

esta poética conoce la esencia de los seres, ella gusta de considerar los actos y los discursos que son bellos y buenos, y ella conduce a una expresión buena en el metro y el ritmo cada uno de los temas que trata. Tú podrías encontrar, de parte de buenos poetas, cantidad de productos de esta clase, todas obras admiradas de gente de buen sentido, plena de admoniciones y de consejos excelentes, colmados de inteligente moderación, que dan los medios, a la gente dotadas de buenas cualidades naturales, de participar en la prudencia y en las otras virtudes, y que hacen acordarse de las revoluciones del alma y de las razones eternas implicadas en estas revoluciones (In Rem I 179.6-15).

Las últimas líneas de este pasaje nos retrotraen al Timeo platónico y al valor que le concedieron los neoplatónicos en su concepción del alma como intermediaria entre lo inteligible y lo sensible y, en consecuencia, siendo compuesta por los círculos de lo mismo y de lo otro, a la vez que para poder pensar, conocer verdaderamente ella debe

\footnotetext{
${ }^{6}$ Cf. Van den Berg (2001, p. 118). Para la crítica de Beierwaltes (1998, pp. 262-268). Aunque la posición de la estudiosa inglesa no parece muy clara en cuanto en uno de sus últimos trabajos habla de "una clase educacional de poesía que ofrece consejos morales, relacionados a la vida en la cual el alma opera en acuerdo con el intelecto y el conocimiento"( Sheppard, 2017, p. 279).
} 
Proclo: el papel soteriológico de la poesía inspirada

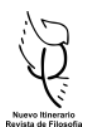

corregir las revoluciones de su intelecto las cuales son fruto de su inserción en un cuerpo físico y de su vida sumergida en las pasiones. En lo que a nuestro tema compete este corregir las revoluciones implica considerar que el alma, como la entiende el Licio, es un plērōma tōn logōn (In Tim. II 200,21) a la vez que es una imagen del intelecto. Ello implica que para poder conocer el alma debe desplegar, es decir, proyectar estos logoi que no son más que imágenes de las formas que el Intelecto posee, por ello es que el alma es un nous aneiligmenos al decir del pasaje IV 896-897 del Comentario al Parménides o un nous elattōn del Comentario al Timeo I 215,15-17, pero esto no es posible si ella no se convierte a sí misma, si no vuelve sobre sí misma. Con otras palabras, sin la presencia de sí misma a sí misma no se hace ella más diáfana y esencial. En consecuencia, para que este desplegar o desenrollar sus razones eternas sea efectivo ella debe abandonar lo múltiple, lo fragmentado, lo disperso, lo parcial, o sea, debe dejar las sombras y los ídolos que son propios de la mimēsis phantastikē y que la hunden en una vida mezclada de opiniones e imaginaciones, que aumenta groseramente las pasiones, la parte pasional del alma llevándola al placer y al dolor (In Rem 179.17-20).

Esta búsqueda del verdadero conocimiento y, por tanto, de la obtención de la ciencia por el alejamiento de lo múltiple y el descubrimiento del alma a sí misma es explicado del siguiente modo en el Comentario al Alcibíades 250.20-251.10:

Porque su esencia está plena de estas razones (las razones eternas de los seres), pero todo esto está oculto por el olvido debido al mundo de la generación, y cuando el alma busca la verdad, ella mira hacia otras cosas, mientras que ella la posee por esencia, y ella busca en otros seres el bien, alejándose de sí misma. Porque si nosotros arrojamos los ojos sobre la multitud de hombres, nosotros no podremos ver nunca su única forma, que está oscurecida por lo múltiple, por lo fragmentario, la separación y los cambios de toda clase de aquellos que participan en ello; si al contrario nosotros nos convertimos hacia nosotros mismos, allí nosotros veremos tanto la razón única como la naturaleza única de los hombres en su pureza.

Este pasaje me parece altamente ilustrativo porque muestra bien la relación entre la vida en la multiplicidad, en la génesis y las sombras que impiden el conocimiento, el verdadero conocimiento que exige la presencia del alma a sí misma. Ello está 
expresado magistralmente en el vocabulario utilizado aquí que refuerza el desdén por la poesía mimética como un hechizo o embrujo.

El mundo de la generación produce olvido porque es el lugar de la dispersión, de la desemejanza, de lo múltiple que se opone a la esencia, a la estabilidad, a la verdadera vida noética, a la vida unificada y uniforme; la no presencia del alma a sí misma, apheisa, más literalmente el abandono de sí, el alejamiento de sí o separarse de sí misma del alma. Proclo parece demandar con ello una mayor interioridad, una mayor exigencia de estar consigo misma para el alma no sólo para conocerse sino también para conocer verdaderamente los seres. Olvido y abandono de sí van de la mano en una vida sumida en las pasiones y en las sombras, y precisamente el participio episkiazomenon nos retrotrae a la skiagrafia de la poesía mimética, al oscurecimiento o al engaño de la pintura de sombras. Por contraposición con ello, la demanda de convertirse el alma a sí misma para tener un conocimiento unificado, acordarse de sí misma como poseyendo los logoi de los seres para al desplegarlos tener ciencia.

Desplegar, desenrollar, anelittein ${ }^{7}$ es la actividad propia del alma que se expresa en su pensar dianoético o discursivo, y ello es reflejar la vida unitaria del Intelecto como poseedor genuino de las Formas. En efecto, el Comentario a los Elementos de Euclides 4, 8 dice acerca de la diánoia que ella

es de hecho segunda respecto al Intelecto y a la suma sabiduría, pero es más perfecta que la opinión, y frente a esta, más rigurosa y más pura, ella en efecto, discurre y despliega lo que es indiviso en el Intelecto, desenrolla lo unificado de las intuiciones intelectivas y luego a su vez reúne las cosas que ha dividido y las refiere al Intelecto.

Todo ello es un movimiento de síntesis y análisis porque en 16, 12 afirma que: Intelecto, en efecto, es también el alma que se despliega según el Intelecto que le es anterior, deviniendo imagen de aquel y su impronta externa (nous gar esti psychē kata

\footnotetext{
${ }^{7}$ Para esta metáfora en el neoplatonismo véase D. Taormina (2007, pp. 215-256) y E. Gritti (2012, pp. 204-210).
} 
Proclo: el papel soteriológico de la poesía inspirada

ton pro autou noun anelitton heauton kai eikon ekeinou kai typos exo genomenos) lo que también señala Teología Platónica I, 19: psychē gar anelittei ton noun.

Ahora bien, la metafísica, como ciencia, es una función de la razón discursiva: ella utiliza la definición, la división, la demostración y el análisis. En razón de una aproximación adecuada al conocimiento perfecto de las ideas como su objeto, la razón discursiva se relaciona más bien con las imágenes o proyecciones de ellas que, en cuanto tales, se prestan mejor a los métodos del pensamiento discursivo. Estas imágenes o proyecciones son en realidad nociones en cierta medida innatas en el alma que son el reflejo de las realidades transcendentes, simples, divinas o superiores y cuyo estudio permite al alma prepararse para su acceso en una visión intelectual o simple de las ideas y de los principios primeros. En esta perspectiva el lenguaje cumple un papel fundamental a la hora de lograr un acceso dialéctico a las realidades trascendentes ya que en tanto imagen el nombre no tiene necesidad de ninguna otra cosa más que la referencia a un modelo del cual puede revelar o manifestar la esencia. Es la función semántica del nombre la que lo hace afín naturalmente a la cosa revelada, y es esta función la que es descripta por la relación que una imagen tiene con su modelo. Tal relevancia de la naturalidad de los nombres o palabras, por así decirlo, está presente en el texto que hemos citado anteriormente de la Teología Platónica en donde Proclo dice que los discursos son una imagen de las realidades a las cuales se refieren y por ello son sus exégetas. La misma idea está presente en el Comentario al Alcibíades I, 22,10 ss cuando afirma:

porque siempre los discursos imitan las realidades de las cuales ellos son los intérpretes. En el Crátilo Sócrates dice que los nombres atribuidos a las realidades eternas comprenden más a la naturaleza de las cosas, mientras que aquellos atribuidos a las realidades sometidas a generación y corrupción varían de múltiples formas y poseen un fuerte elemento convencional a causa del movimiento inestable de los sustratos a los cuales se relacionan.

Los aspectos del método metafísico que hemos mencionado anteriormente, la definición, la división, la demostración y el análisis se insertan en una perspectiva general que comprende dos direcciones: una fase de ascenso hacia el Primer Principio, 
y una fase de descenso que describe la progresión de los seres a partir de este Principio. Las dos fases, ascenso y descenso, que se aplican según Proclo al Parménides, nos recuerdan evidentemente el ascenso y descenso del alma en la alegoría de la caverna de la República de Platón.

La mención a esta última obra de Platón nos permite comprender más claramente el modo en el cual Proclo exige del alma una verdadera conversión hacia sí misma para poseer la ciencia que conoce la esencia de los entes y hacer una poética epistémica que "opera con entendimiento y sabiduría, que ha revelado a los hombres algunas nociones de la naturaleza incorpórea" (In Rem I. 186.24-26), lo que se explicita muy bien en el siguiente pasaje del Comentario a los Elementos de Euclides 44, 5-17:

\begin{abstract}
En efecto las sensaciones ponen al alma en contacto con las cosas divisibles; por un lado las apariencias la colman de movimientos creadores de simulacros, por otro los deseos la vuelcan hacia una vida pasional. Ahora bien todo lo que es fragmentario es un impedimento a un replegarse en sí misma, y todo aquello que crea formas ilusorias turba el conocimiento puro, y toda pasionalidad es un impedimento a su impasible actividad. Cuando pues se logra remover estos obstáculos del conocimiento dianoético, entonces podremos conocer las razones que el alma tiene en sí misma y ser efectivamente instruidos y proyectar de ella un conocimiento esencial. Pero prisioneros como estamos, y cerrado el ojo del alma jamás podremos obtener la perfección que nos conviene.
\end{abstract}

Hasta aquí se ha advertido el proceso de conversión o retorno de lo inferior hacia lo superior expresado en alejarse de lo múltiple para lograr la unificación, es decir, el alma debe abandonar su propia multiplicidad y unificarse. Ello es expresado en el marco del análisis de las formas poéticas con un claro lenguaje epistemológico de repercusiones éticas. En efecto, hay que hacer el camino inverso de la procesión, o sea, elevarse desde la doxa a través de la dianoia hacia el nous para superarlo, trascenderlo, o digámoslo mejor, para abandonarlo y alcanzar lo Uno inefable en una experiencia extática. En tal sentido cabe señalar que la concepción que subyace en esta exposición de las tres hipóstasis es bastante sugestiva del modelo plotiniano más que de aquel bastante alambicado que forja Proclo en su desarrollo, tanto que puede decirse que no hace más que desplegar las profundas intuiciones de Plotino. 
Proclo: el papel soteriológico de la poesía inspirada

La primera forma de poesía, la más elevada y suprema, la divinamente inspirada muestra una vida del alma en la cual efectivamente esta abandona su intelecto, lo deja a un lado para acceder a la suprema unificación. Ella debe hacer resplandecer en sí misma el "uno del alma". En este estado o en este hábito o modo de ser ella está unida a los dioses en virtud de la semejanza y vive una vida que no le pertenece, que no es propio de ella.

Cabe realizar aquí una observación textual de profundas consecuencias hermenéuticas para la pregunta que nos hemos planteado al comienzo de estas páginas.

La traducción de Festugiére, siguiendo el códice Laurentianus y a Kroll vierte las líneas 17-20 del pasaje I 177 del siguiente modo: “...según la cual el alma se une a los dioses y vive la vida que le es más connatural y unida por la semejanza más alta, vida que no se pertenece a ella misma, sino a los dioses...", por el contrario Lamberton en su edición de las disertaciones V y VI prefiere seguir el códice Basel de 1534 y lee: "...vida en la cual el alma no se pertenece a ella misma sino a los dioses...".

Lectura que parece en efecto ser la más adecuada y correcta si se tienen en cuentan los pasajes siguientes. En I 180. 25.27 Proclo afirma describiendo precisamente esta poesía inspirada, inspirada platónicamente en Fedro 245 a como fuente, y sus efectos en el alma, que las iluminaciones que vienen de lo alto son las presencias divinas y que el iluminado se abandona a los movimientos que vienen de allí y abandona su propio modo de ser, se somete a las influencias del ser divino: to d'ellampomen heauto tais ekeithen kineseon..tōn spheteron ethōn existamenon hypestrotai tais tou theiou kai monoeidous energeiais, y unas líneas más adelante, en I 181. 7 afirma que heautēs gar estin mallon è tou ellampontos kai ouk eutypotos pros tēn ekeithen dosin (porque es más de sí misma que del que ilumina y no es fácilmente receptiva a sus dones), para referirse a un alma dura y resistente que se opone a seguir los movimientos que vienen de lo alto.

Suscribo aquí la lectura de Lamberton porque entiendo no sólo que ella da fundamentos a mi hipótesis de lectura sino también porque entiendo que la clave de 
este pasaje está en el participio existamenon, término de profundas y resonantes repercusiones místicas. Por tanto, nos preguntamos nuevamente: ¿Es Proclo un mero teórico de la mística como afirma Sheppard? 0 ¿debemos decir que es más bien un pensador religioso y místico, como afirma Lamberton, que busca más allá del texto la experiencia de lo divino?

Por su parte Van den Berg (2011, p.116) señala lo siguiente: "Esta forma de vida es aquella de la experiencia mística última de la unificación última del alma. Esta forma de vida desciende para devenir semejante a dios tanto como es posible con el resultado que el alma sobrepasa las limitaciones de su propia existencia". Sin embargo, el pensador holandés aunque describe muy bien la unificación del alma no desarrolla exhaustivamente su afirmación.

A mi modo ver, para comprender la posibilidad de que Proclo es un místico y que la forma inspirada de poesía abre las puertas a tal comprensión no puede soslayarse el vocabulario que utiliza para aludir a la experiencia extática del alma.

No solamente el uso del participio existamenon sino también el uso del término synthēma para referirse al despertar del alma en ella de este símbolo inefable de los dioses, o sea, el alma lleva en sí la presencia divina que debe despertar cuando se aleja de las apariencias engañosas de lo sensible para retornar a su Luz originaria al vincular lo semejante que hay en ella con lo semejante de allá, su luz con aquella Luz, lo que hay de semejante a lo Uno en ella con lo Uno más allá de toda esencia. Estas ideas que están condensadas en esta descripción de la poesía inspirada encuentran su mayor explicitación en el siguiente pasaje del Comentario al Alcibíades 247. 8:

Y después del intelecto tan estimado es necesario despertar la existencia suprema misma del alma, gracias a la cual nosotros somos uno y por la cual es unificada la multiplicidad que está en nosotros. Porque lo mismo que tenemos parte en el intelecto según el nombrado intelecto, lo mismo también tenemos parte en el Primero, del cual viene, para todos los seres la unidad, y por lo uno y, por así decir, la flor de nuestra esencia, la cual nos une muy particularmente a lo divino.

El mismo tenor de ideas encontramos tanto en el Comentario al Parménides VI 10711072 como en Teología Platónica I, 3-4. 
Proclo: el papel soteriológico de la poesía inspirada

En consecuencia, el alma se une a lo supremamente Uno en virtud del "uno del alma". Despertar esta fuerza motora del alma por acción del intelecto significa hacernos uno, unificar la multiplicidad en nosotros. Cuando obra el "uno del alma", cuando resplandece esa imagen divina escapamos a la dispersión; así nuestros actos son cada vez más uniformes y nos concentramos en nuestra henōsis. Cada vez que nos alejamos de la multiplicidad y, por lo tanto, nos acercamos a lo Uno, cuando nos trascendemos a nosotros mismos, nos elevamos hasta ese "uno y flor del alma" porque "es por lo Uno que conocemos lo Uno" (In Parm VI 1081).

Ahora bien, el nombrar a este "uno del alma" como synthēma, hyparxis, symbolon y flor del alma exige considerar lo que Proclo ha plasmado en su Comentario a los Oráculos Caldeos, porque cuando describe el modo en el cual entiende esta poesía inspirada diciendo que en ella por una cierta henōsis arrētos se da una identidad entre lo que es colmado y aquel que colma, sometiendo el uno, inmaterialmente y sin contacto, a la iluminación, excitando al otro a dar parte en su Luz cita Oráculos Caldeos 54: "realizando las obras de los conductos mezclados de fuego indestructible". Sabemos de la relevancia de estos hexámetros poéticos en el neoplatonismo tardío tanto en su metafísica como en su psicología. En este último punto son relevantes los fragmentos 108, 109 así como el frag. $V$ del Comentario de Proclo en el cual señala que el alma está compuesta de logoi noeroi y theia symbola.

En el fragmento IV de su Comentario a los Oráculos Caldeos Proclo aplica el principio de que lo semejante conoce lo semejante -como en In Parm VI- y afirma que

el alma...cuando ha corrido hacia lo Uno y ha recogido juntamente la multiplicidad toda que hay en ella, actúa inspiradamente y se enlaza con las realidades que están sobre el intelecto, pues por doquier lo semejante tiene natural disposición a unirse con lo semejante...de tal modo también la flor del intelecto a lo que es anterior al intelecto...Porque, de igual modo que tomando forma de intelecto nos aproximamos al Intelecto, así también tornándonos uniformes corremos hacia la unión.

La flor del intelecto es la actividad no más pensante, la actividad divinamente inspirada que aparece, que se despierta cuando el alma, en su anhelo por lo Uno, corre hacia la unión habiendo abandonado toda intelección y estableciéndose en la cima de 
todo lo inteligible (cf. Com. Or. Cal. IV; In Parm VI 1072). Este despertar es descripto maravillosamente en In Rem I 178.20-27 al hablar sobre la singularidad de la poesía inspirada cuando afirma que: "despertar consiste en que el alma tienda y actúe sin espíritu de retorno y en que ella se desvíe de la caída en la génesis para convertirse hacia lo divino". Este despertar es un delirio o una manía superior a un estado mesurado, temperado del alma, es decir, una superación del noûs para hacer aparecer un estado supradiscursivo e intuitivo, una experiencia extática. (cf. In Rem I 178.25; 181.19-27; In Alc. 49.8). Este pasaje puede considerarse una exégesis sucinta de Fedro $244 d-245 a$ y en el cual Proclo hace su más viva defensa del poder soteriológico de la poesía inspirada. En efecto, unas líneas más adelante afirma que "esta poética inspirada, pues, Platón la ha llamado, en el Fedro, una posesión de las Musas y un delirio, que es concedida desde lo alto a un alma tierna e impoluta"

Ello es posible porque según Proclo, Platón no ha censurado todo tipo de poesía, sino solamente aquella mimética que sumerge al alma en las apariencias, pero ha valorizado aquella epistémica e inspirada. Por ello también es que Platón y Homero no discrepan en lo fundamental sino que se aúnan en el poder soteriológico de la poesía simbólica, de aquella que produce la salvación de las almas.

En efecto, Proclo aclarando que Platón en Rep. $X$ no censura a Homero sino a la mimēsis phantastikē afirma que la poesía de Homero toma su impulso de los dioses y revela la naturaleza de los seres, por ello es que se pregunta:

¿Cómo se podría llamar imitación la poesía que interpreta las cosas divinas por medio de símbolos? Porque los símbolos de las realidades de las cuales ellos son los símbolos no son imitaciones (In Rem I 198.15-17).

Decir entonces que la poesía inspirada es una poesía simbólica y soteriológica es reconocer el profundo carácter religioso que anida en la noción de símbolo, sinónimo de synthēma para el Licio. Los símbolos no son arbitrarios, o convencionales, ellos poseen un contenido sagrado que se hace necesario interpretar y desentrañar porque a través de ellos se manifiesta la vida mejor y más perfecta del alma, pero claro está, para que esto sea posible el alma debe retornar hacia lo divino alejándose de las apariencias, de lo fenoménico, de lo fragmentario, de la vida multiforme que genera la 
génesis con sus sombras e ilusiones, al igual que el abandono de las pasiones o una vida sumida en las pasiones. Expresado con otras palabras, el símbolo literario o poético es como el símbolo de los ritos teúrgicos, es decir, es cierto mecanismo que estimula el proceso ascendente de reversión; las palabras que el poeta utiliza en su lenguaje simbólico son anagógicas en un sentido muy concreto, apuntan a la unión anagógica con lo Uno. Por ello es que el poeta inspirado no puede realizar una representación mimética del tema del cual habla sino que por el contrario invoca su presencia real, la presencia divina. De ese modo los símbolos literarios operan sobre aquella parte del alma que porta una huella de lo divino y despiertan el símbolo de lo divino, sembrado en ella, y con el cual ella está relacionada; porque ellos son una huella trascendente desplegada desde un orden superior. Los símbolos poéticos y míticos pueden realizar este carácter operatorio y soteriológico porque son evocadores e invocadores de una gracia salvadora, cuales fragmentos limitados de esta. Los símbolos literarios "tienen la misma clase de poder performativo que los símbolos de la teúrgia. No es casualidad que Proclo utilice el mismo término (symbolon/synthēma) en ambos contextos...como el synthēma manipulado por los teurgistas, los símbolos poéticos nos transportan a un estado del alma que no puede ser alcanzado por medios ordinarios" (Chlup, 2012, p.192) ${ }^{8}$. En tal sentido no conllevan en sí una semejanza con su referente sino que invocan la presencia real de su referente, poseen un poder evocativo muy singular para ligar el alma con lo divino.

Un estado divinamente inspirado que trasciende las condiciones normales de intelección, y que por tanto supera la comprensión científica, es decir, todo estado intelectivo al cual puede llevar una poesía epistémica es el fruto del poder soteriológico de los símbolos poéticos. Con otras palabras, trascender el intelecto para despertar el símbolo divino que el alma lleva en sí, despertar la posesión divina.

Aquí cobra todo su relieve el pasaje del Comentario al Alcibíades que hemos citado en las primeras páginas de esta comunicación acerca de las tres clases de conversión o de retorno. Alejarse de las apariencias es volverse el alma hacia sí misma, recuperarse, recobrarse, conocerse, estar más presente a sí misma, y en esta presencia

\footnotetext{
${ }^{8}$ Para una perspectiva opuesta a la identificación entre symbolon y synthema véase Cardullo (1985).
} 
descubrir que es imagen del Intelecto, que su pensar dianoético es un desplegar lo unificado del nous. Pero este no es el principio supremo, hay algo más hacia lo cual aspira en su deseo, deseo que se explicita en el despertar de los símbolos divinos que hay en ella, los cuales aluden a lo que escapa a todo lenguaje y a todo discurrir, y que solamente puede experimentarse en una henōsis inefable cuando ella se deja colmar por lo divino. Decir "colmar" no es una metáfora sino la expresión clara de la experiencia de lo divino, de lo supremamente inefable, porque todo grado de ser inferior es por relación a su superior algo hueco, un vacío a colmar. Por ello es significativo que Proclo hago uso constante del verbo plēroun (cf. In Rem I 178.14-28; 180.19), lo que dejar traslucir bellamente la siguiente frase: "Platón ha llamado a una tal iluminación posesión y delirio: la ha llamado posesión en tanto que ella se hace señora de todo lo que es movido por ella, y la ha llamado delirio en tanto que hace renunciar a los iluminados a sus actividades ordinarias para atraerlos hacia su propia especificidad" (In Rem I 180.29-181.3), de ese modo hace "que lo más divino sea lo único que obra, desde allí que lo inferior se ha encogido y oculta su propia naturaleza en lo superior" (In Rem I 178. 22-24).

La flor del intelecto, el "uno del alma", es esa semilla de aquel No-Ser sembrada en nosotros que se despierta cuando el alma pone en quietud todas sus potencias por acción del intelecto, acción inspirada, es decir, actividad no más pensante sino la más unificadora y la más unificada.

Esta actividad no más pensante, este no-conocer, por el cual el intelecto se acerca y se asemeja a lo Uno cobra un relieve singular, tiene una importancia espiritual de vasto alcance a la hora de comprender que ella es el espacio, el lugar, por decirlo de algún modo, donde se realiza la experiencia extática, espiritual o mística. Con otras palabras la experiencia espiritual, la experiencia mística que es posible por la flor del intelecto, el «uno del alma», muestra que esa actividad no-intelectual -que es comunión extática con lo Uno- hace necesario trascender toda discursividad, toda intelectualidad para unificarse y de ese modo deificarse (cf. In Parm VI 1066, 1109). Por esa actividad que no es intelectiva sino inspirada, fruto de la máxima unificación 
Proclo: el papel soteriológico de la poesía inspirada

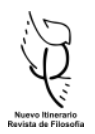

que se expresa en la flor del intelecto Proclo expresa su experiencia espiritual, su experiencia mística, que no es sino la salvación del alma.

Una experiencia espiritual que comenzó con la exhortación al despojamiento absoluto de todo lo extraño a la verdadera vida del alma para que ésta, despertando el uno del alma, se embriague en comunión extática con lo Uno danzando en torno a él (cf. In Parm VI 1080) en cuanto este despojamiento implica reconocer que "más la negación se profundiza, más atestigua que es la divinidad la que niega en nosotros" porque "en Proclo, como en Plotino, <la mística> no es de ningún modo la conquista, sino el origen de toda la vida del espíritu y del esfuerzo filosófico mismo. Ella es menos superior que anterior, menos supraesencial que preesencial" (Trouillard, 1982, p.75)

Referencias bibliográficas

Proclus. Commentaire sur la République I-III. Traduction et notes par A. Festugiére (1970). Paris: Vrin.

Proclus. Commentary on Plato'Republic. Volume I. Essays 1-6. Edited and translated by D. Baltzly, J. Finamore and G. Miles (2018). Cambridge: CUP.

Proclo. Commento al I Libro degli Elementi di Euclide, Introduzione, traduzione e note a cura di M. Timparano Cardini (1978). Pisa: Cisalpino.

Proclus. Sur le Premier Alcibiade de Platon I-II. Texte établi et traduit par A. Segonds (1985-1986). Paris: Les Belles Lettres.

Abbate, M. (2012). Tra Esegesi e Teologia. Studi sul neoplatonismo. Milano: Mimesis.

Beierwaltes, W. (1998). Pensare l' Uno. Milano: Vita e Pensiero.

Bouffartigue, J. (1987). Représentations et évaluations du texte poétique dans le Commentaire sur la République de Proclos. En Études de Littérature Ancienne 3: Le texte et ses représentations, 129-143. PENS: Paris. 
Cardullo, L. (1985). Il linguaggio del símbolo in Proclo. Analisi filosoficosemantica dei termini symbolon/eikôn/synthêma nel Commentari alla Republica. Catania: Symbolon

Chlup, R. (2012). Proclus. An Introduction. Cambridge: CUP.

Gritti, E. (2012). Il vero nel mito. Teoria esegetica nel commento di Olimpidoro Alessandrino al Gorgia. Roma: Aracne.

Hadot, P. (2006). Ejercicios Espirituales y Filosofía Antigua. Barcelona: Siruela.

Halliwell, S. (2009). L'estetica della mimesis. Testi antichi e problema moderni. Palermo: Aesthetica.

Lamberton, R. (1986). Homer the Theologian. Neoplatonist Allegorical Readings and the Growth of Epic Tradition. Los Angeles: UCP.

Lamberton, R. (2012). Proclus the Succesor on Poetics and the Homers Poems: Essays 5 and 6 of His Commentary of the Republic of Plato. Translated and with an Introduction and Notes. Atlanta: SBL.

Moutsopoulos, E. (2010). La Filosofia della música nel sistema di Proclo. Milano: Vita e Pensiero.

Moutsopoulos, E. (1981). Sur la notion d'eidolon chez Proclus. En Nêoplatonisme. Melanges offerts a Jean Trouillard. Les Cahiers de Fontenay: ENS.

Napolitano Valditara, L. (2007). Platone e la ragioni dell'immagine. Percorsi filosofici e deviazioni tra metafore e miti. Milano: Vita e Pensiero.

Rappe, S. (2000). Reading Neoplatonism. Non-discursive thinking in the texts of Plotinus, Proclus and Damascius. Cambridge: CUP.

Sekimura, M. (2009). Platon et la question des images. Bruxelles: Ousia.

Sheppard, A. (2013), Proclus'place in the reception of Plato's Republic. En A. Sheppard (ed), Ancient Approaches to Plato's Republic (pp.206-216). London: BICS.

Sheppard, A. (1980). Studies on the 5th and 6th Essays of Proclus'Commentary on the Republic. Gottingen: Vandenhoeck\&Ruprecht.

Sheppard, A. (2017). Literary Theory and Aesthetics. En P. d'Hoine-M.Martin (ed.), All from One. A Guide to Proclus(pp.276-289). Oxford: OUP.

Struck, P. (2004). Birth of The Symbol. Ancient Readers at the Limits of Their Texts. Princeton: PUP. 
Proclo: el papel soteriológico de la poesía inspirada

Taormina, D. (2007). Dynamiques de l'écriture et processus cognitif dans le néoplatonisme (Jamblique, Plutarque d'Athènes, Priscien de Lydie et Proclus). En M. Dixsaut. Contre Platon I (pp.215-246). Paris: Vrin.

Trouillard, J. (1982). La mystagogie de Proclos. Paris: Les Belles Lettres.

Trouillard, J. (2014). Le symbolisme chez Proclus. En Raison et Mystique. Études Néoplatoniciennes. Paris: Cerf.

Van den Berg, R.M. (2001). Proclus' Hymns. Essays, translations, commentary. Leiden: Brill. 